\title{
Vértebra limbus
}

\author{
Vertebra limbus \\ Luis Gerardo Domínguez Carrillo, ${ }^{*}$ Luis Gerardo Domínguez Gasca ${ }^{\ddagger}$ \\ Citar como: Domínguez CLG, Domínguez GLG. Vértebra limbus. Acta Med Grupo \\ Angeles. 2021; 19 (2): 300-301. https://dx.doi.org/10.35366/100463
}

Femenino de 17 años que acude por defectos posturales. A la exploración se encontró cifosis dorsal e hiperlordosis lumbar, por otro lado asintomática, se solicitaron radiografías de columna encontrando como hallazgo incidental dos vértebras limbus.

El hueso limbus fue descrito por Schmorl en 1927, es un osículo adyacente en el borde anterior, habitualmente superior, de un cuerpo vertebral, (a la vértebra que lo presenta se le ha denominado vértebra limbus) pero pueden observarse con menor frecuencia en los márgenes anteroinferior

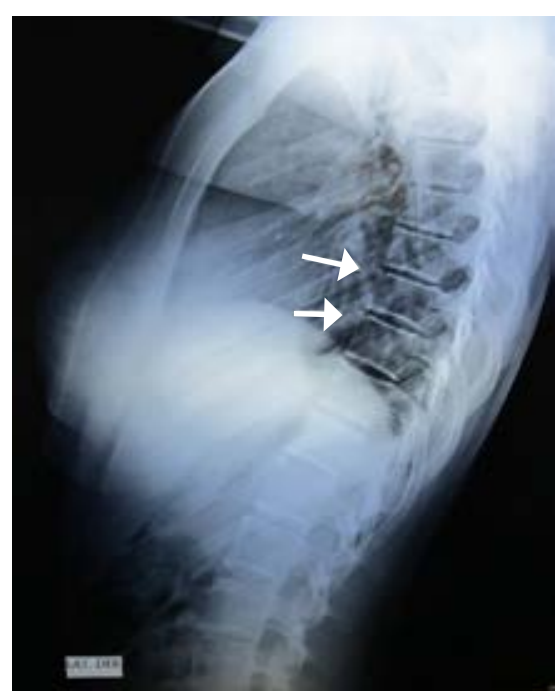

Figura 1:

Radiografía lateral de espina dorsal y lumbar, mostrando cifosis dorsal e hiperlordosis lumbar de tipo postural, como hallazgo se observan C6 y C7 catalogadas como vértebras limbus (flechas).

\footnotetext{
* Especialista en Medicina de Rehabilitación, Catedrático de la Facultad de Medicina de León, Universidad de Guanajuato, México.

₹ Ortopedista. Cirugía articular. División de Cirugía del Hospital Ángeles León, León, Guanajuato, México.
}

Correspondencia:

Luis Gerardo Domínguez Carrillo

Correo electrónico: Igdominguez@hotmail.com

Aceptado: 15-06-2020.

www.medigraphic.com/actamedica

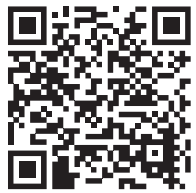

o posteroinferior; representan una herniación intraósea del núcleo pulposo a través del anillo apofisario vertebral, antes de su fusión completa en el esqueleto inmaduro; ${ }^{1}$ habitualmente es asintomático y suele diagnosticarse como un encuentro radiológico incidental, se percibe con mayor frecuencia en la región lumbar, en donde se ha relacionado
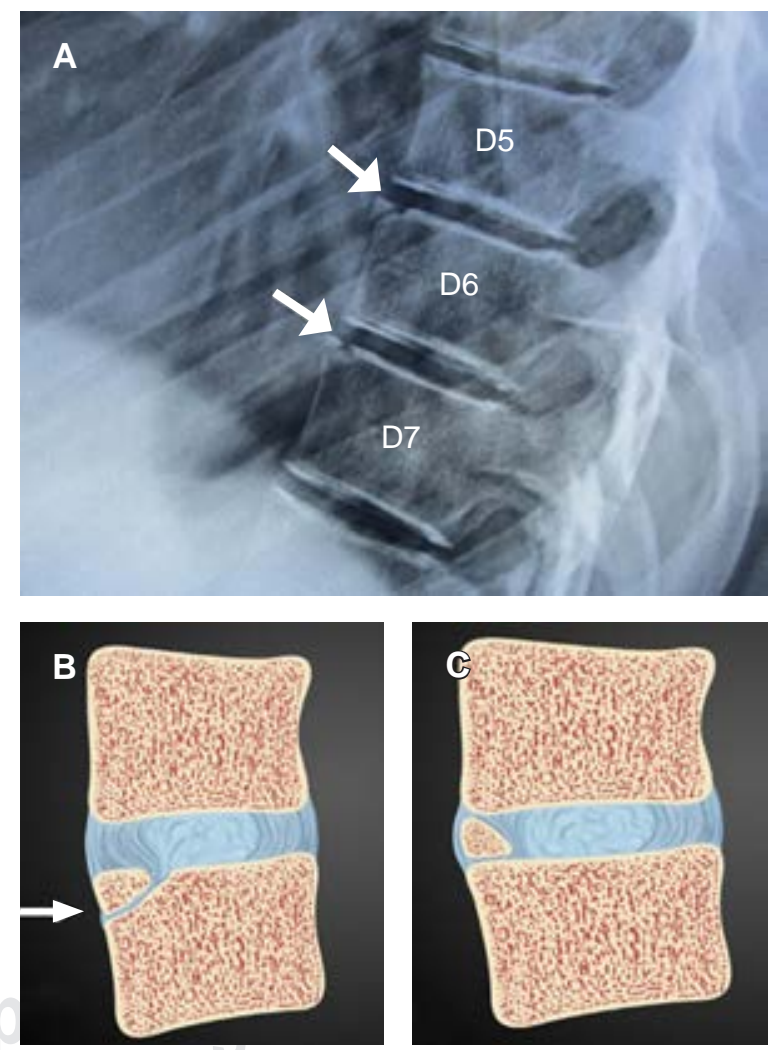

Figura 2: A) Radiografía lateral de columna lumbar mostrando a las vértebras C6 y C7 con defecto triangular en borde superior, correspondiendo a hueso limbus (flechas). B) Esquema demostrativo de herniación intraósea del núcleo pulposo a través del anillo apofisario vertebral (flecha). C) Esquema que muestra un hueso intercalar como diagnóstico diferencial. 
con lumbalgia mecánica en jóvenes, ${ }^{2}$ mientras que es menos común en las regiones cervical y dorsal. La radiografía lateral de columna es suficiente para el diagnóstico, se advierte un defecto óseo radiolúcido similar a una banda oblicua bien definida en el margen anterosuperior del cuerpo vertebral, que aísla un pequeño fragmento óseo triangular, de márgenes bien definidos, separado del cuerpo vertebral. $^{3}$ El diagnóstico diferencial debe efectuarse con fractura límbica, espondilodiscitis, tumores vertebrales, hernias intraesponjosas de Schmorl, fractura en lágrima y hueso intercalar (Figuras 1 y 2). ${ }^{4}$

\section{REFERENCIAS}

1. Ghelman B, Freiberger RH. The limbus vertebra: an anterior disc herniation demonstrated by discography. AJR Am J Roentgenol. 1976; 127 (5): 854-855.

2. Restrepo JP, Molina M, Vértebra limbus, rara causa de dolor lumbar en jóvenes. Rev Colomb Reumatol. 2020; 27 (2): 120-122. doi: 10.1016/j.rcreu.2019.03.004.

3. Torres HJ, Rodríguez MS, Pérez AR, Limbus vértebra Sem. Fund Esp Reumat. 2012; 13: 62-64. doi: 10.1016/j.semreu.2011.12.002.

4. Carr RB, Fink KR, Gross JA. Imaging of trauma: Part 1, Pseudotrauma of the spine--osseous variants that may simulate injury. AJR Am J. 2012; 199 (6): 1200-1206. doi: 10.2214/AJR.12.9083. 